
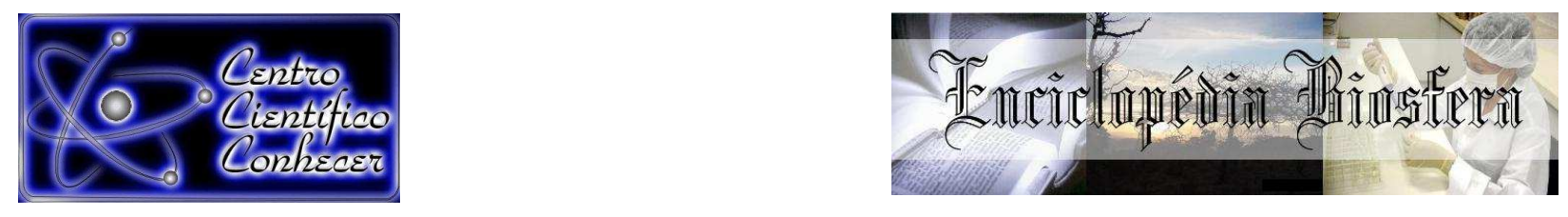

\title{
AGENTES ANTINEOPLÁSICOS PARA O TRATAMENTO DO OSTEOSSARCOMA
}

Gabriela Hadler Gabriel $^{1}$, Leandro Lopes Nepomuceno ${ }^{2}$, Vanessa de Sousa Cruz Pimenta ${ }^{3}$, Eugênio Gonçalves de Araújo ${ }^{4}$

1 Mestranda do Programa de Pós-Graduação em Ciência Animal da Escola de

Veterinária e Zootecnia da Universidade Federal de Goiás (gabriela.hadler@hotmail.com). Goiás-Brasil

2 Doutorando do Programa de Pós-Graduação em Ciência Animal da Escola de

Veterinária e Zootecnia da Universidade Federal de Goiás

3 Pós doutoranda, Laboratório Multiusuário de Cultivo Celular da Universidade Federal de Goiás

4 Prof. Doutor do Setor de Patologia Veterinária da Universidade Federal de Goiás

Recebido em: 02/10/2017 - Aprovado em: 21/11/2017 - Publicado em: 05/12/2017 DOI: 10.18677/EnciBio_2017B2

\begin{abstract}
RESUMO
O osteossarcoma é o tumor ósseo de maior ocorrência, sendo seu estudo importante nas espécies humana e canina. As crianças e jovens são mais frequentemente acometidas, por estarem em uma idade quando ocorre maior crescimento ósseo, sendo que o contrário ocorre nos animais, que são acometidos geralmente com idade avançada entre seis a 10 anos. A etiologia do tumor é desconhecida e as taxas de mortalidade são altas, variando de 40 a $50 \%$ para os humanos e chegando até $80 \%$ nos animais. O tratamento é baseado na remoção cirúrgica do tumor e quimioterapia, associação esta que permitiu melhora nos resultados dos tratamentos, mas cursa com intensa toxicidade e inúmeros efeitos adversos para os pacientes. Sem melhora significativa nas taxas de cura nos últimos 30 anos, a busca de tratamentos alternativos para o osteossarcoma é necessária para aumentar a expectativa de vida dos pacientes e diminuir a ocorrência de efeitos adversos.
\end{abstract}

PALAVRAS-CHAVE: oncologia comparativa, quimioterapia, toxicidade.

\section{ANTINEOPLASTIC AGENTS FOR THE TREATMENT OF OSTEOSARCOMA}

\begin{abstract}
Osteosarcoma is the most frequent bone tumor, being important in both medicine and veterinary medicine. Children and youngsters are more frequently affected because they are at an age where there is greater bone growth, whereas the opposite occurs in animals, which are usually affected at an advanced age between 6 and 10 years. The etiology of the tumor is unknown and mortality rates are high, ranging from 40 to $50 \%$ for humans and up to $80 \%$ in animals. The treatment is based on the surgical removal of the tumor and chemotherapy, an association that allowed improvement in the results of the treatments, but presents with intense toxicity and numerous adverse effects for the patients. Without significant improvement in cure rates over the past 30 years, the search for alternative
\end{abstract}


treatments for osteosarcoma is necessary to increase patients' life expectancy and decrease the occurrence of adverse effects.

KEYWORDS: chemotherapy, osteosarcoma, toxicity.

\section{INTRODUÇÃO}

Os sarcomas ósseos primários são raros e representam menos de 0,2\% de todos os novos casos de câncer. Dentre esses tumores, o osteossarcoma é o de maior prevalência (FAUSKE et al., 2015), afetando principalmente crianças, adolescentes e jovens adultos (FAUSKE et al. 2015; ISAKOFF et al. 2015). A maior incidência ocorre no pico de estirão do crescimento, geralmente nas duas primeiras décadas de vida, na fase da puberdade (CASTRO et al. 2008). Acomete ossos longos e tubulares, como o fêmur, a tíbia e o úmero. O tumor se caracteriza pela formação direta de osso imaturo ou tecido osteóide pelas células tumorais, com origem na metáfise dos ossos longos (PICCI, 2007).

Nos cães, o osteossarcoma é o tipo mais comum de tumor ósseo, ocorrendo com maior frequência nos animais de raças gigantes, como o Rottweiler, German Shepherd, Boxer, Doberman Pinscher e Irish Setter, geralmente com idade entre 6 a 10 anos. Cerca de 64\% dos casos de osteossarcoma canino acometem o esqueleto apendicular (SZEWCZYK et al. 2015).

A etiologia do tumor é desconhecida nos humanos, mas acredita-se em uma origem viral e, embora nenhum vírus tenha sido isolado, essa hipótese não foi descartada, por já ter sido comprovada experimentalmente em fetos de cães e ninhadas, podendo a causa ser a presença do agente no genoma da célula. Outra possível causa é a ação de radiação ionizante. Além disso, existe predisposição genética, encontrada em pacientes com retinoblastoma, sendo que, nesses pacientes, o osteossarcoma ocorre com frequência 500 vezes maior do que no restante da população não portadora da doença. Cerca de 3 a 4\% das crianças com osteossarcoma apresentam uma mutação na proteína p53 e, a maioria dos casos desse tipo de mutação ocorre em pacientes com histórico familiar sugestivo de Síndrome de Li-Fraumeni (PICCI, 2007).

O osteossarcoma canino também possui etiologia desconhecida, mas existem vários fatores predisponentes, como o gênero do animal e o peso. Os machos e animais com peso superior a 40kg são mais predispostos (SZEWCZYK et al. 2015). Pode existir uma correlação entre a castração e o risco de desenvolvimento do osteossarcoma, sendo que os animais castrados antes do primeiro ano de vida estão mais predispostos ao desenvolvimento da doença (COOLEY et al. 2002).

O tumor é maligno e bastante agressivo, levando 40 a $50 \%$ das pessoas acometidas a morte (HATTINGER et al. 2015) e causando metástases em $85 \%$ dos doentes, tendo o pulmão como principal alvo (ISAKOFF et al. 2015). Nos animais, a taxa de mortalidade é maior, sendo que $80 \%$ dos cães com osteossarcoma morrem devido a metástases no pulmão (SZEWCZYK et al. 2015).

O tratamento atual consiste na remoção cirúrgica do tumor primário com ação da quimioterapia combinada, que se baseia na associação de agentes antineoplásicos (HATTINGER et al. 2015). Com a descoberta de novos quimioterápicos, foi possível elevar a taxa de cura dos doentes até 60 a $75 \%$, sendo que, antes de 1960, a taxa era considerada inferior a 10\% (JAFFE et al. 2013). Na medicina, as drogas mais utilizadas na quimioterapia dos pacientes são a doxorrubicina, cisplatina, metotrexato e ifosfamida (FERRARI et al. 2012). Nos cães, os tratamentos mais utilizados consistem na remoção cirúrgica, radioterapia e 
quimioterapia. As drogas mais utilizadas para o tratamento dos animais incluem a carboplatina, cisplatina e doxorrubicina (SZEWCZYK et al. 2015).

A associação entre a cirurgia e a terapia quimioterápica mudou o cenário do tratamento do osteossarcoma, mas trouxe inúmeras consequências negativas aos pacientes, como a limitação funcional, problemas emocionais e, ainda, distúrbios de infertilidade, que podem ocorrer com o uso de alguns antineoplásicos ${ }^{1}$. Nos animais, a associação entre os tratamentos também promoveu melhoras e reduziu a ocorrência de metástases, mas vários são os efeitos tóxicos dos medicamentos utilizados (SZEWCZYK et al. 2015).

O uso de protocolos quimioterápicos com associação de três drogas apresentou resultados melhores do que os obtidos na utilização de duas drogas associadas, porém, essa intensificação no tratamento aumentou ainda mais a toxicidade e os efeitos adversos nos pacientes (HATTINGER et al. 2015).

Embora a mortalidade dos pacientes tenha diminuído, não houve melhora significativa nas taxas de cura nos últimos 30 anos, o que torna necessário o desenvolvimento de pesquisas sobre novas drogas e tratamentos alternativos, para melhorar os resultados, a expectativa de vida dos pacientes e diminuir os efeitos adversos (HATTINGER et al. 2015; SZEWCZYK et al. 2015).

Diante disso, essa revisão de literatura objetivou reunir os principais agentes antineoplásicos utilizados no tratamento de pacientes com osteossarcoma, pontuando suas vantagens e desvantagens, bem como trazer informações sobre novas drogas e terapias alternativas.

\section{QUIMIOTERAPIA}

A descoberta de agentes quimioterápicos com potencial de atuação nas células de osteossarcoma ocorreu na década de 60. Essa prática baseia-se na administração de agentes antineoplásicos, os quais exercem efeitos citotóxicos nas células tumorais. Um dos benefícios da quimioterapia é o prolongamento da vida do paciente, principalmente quando associada à outras formas de tratamento, como a cirurgia de amputação do membro afetado (SZEWCZYK et al. 2015).

Os antineoplásicos podem ser classificados em diferentes classes de acordo com seu mecanismo de ação (Quadro 1). A maioria possui atuação inespecífica, promovendo lesão tanto nos tecidos normais quanto nas células tumorais. As terapias padrão para o tratamento do osteossarcoma incluem a doxorrubicina ou adriamicina, cisplatina, metotrexato e ifosfamida. A associação entre três drogas atingiu resultados melhores do que os protocolos utilizando apenas uma ou duas drogas combinadas (HATTINGER et al. 2015).

Os quimioterápicos agem destruindo as células tumorais ou impedindo seu crescimento, sendo que os fármacos atuam nas diferentes fases do ciclo celular. Existem os agentes alquilantes, que compõem o grupo de agentes não específicos do ciclo-celular, os quais inibem a replicação celular, e são geralmente usados em combinação com outros agentes antineoplásicos (ALMEIDA et al. 2005).

Dessa mesma forma atuam os agentes platinantes, grupo composto pela carboplatina e cisplatina, que agem por meio da formação de complexos de coordenação de platina, alquilando o DNA e inibindo seletivamente a síntese deste. Além disso, possuem propriedades citotóxicas, relacionadas à formação de ligações cruzadas, e atuam de forma sinérgica com outros agentes antineoplásicos. A cisplatina se difere ainda por ser capaz de provocar mutações no DNA, alterando a ligação que existe entre o DNA e as proteínas (ALMEIDA et al. 2005). 
QUADRO 1 - Classificação dos fármacos antineoplásicos oncológicos.

\begin{tabular}{|c|c|c|}
\hline CLASSE & AÇÃO & FÁRMACOS \\
\hline Agentes alquilantes & Inibem a replicação celular & $\begin{array}{c}\text { Ciclofosfamida } \\
\text { Clorambucil } \\
\text { Melfalan } \\
\text { Lomustine }\end{array}$ \\
\hline Agentes platinantes & $\begin{array}{c}\text { Alquilam e inibem } \\
\text { seletivamente a síntese do } \\
\text { DNA }\end{array}$ & $\begin{array}{c}\text { Carboplatina } \\
\text { Cisplatina }\end{array}$ \\
\hline Antimetabólitos & $\begin{array}{l}\text { Atuam na síntese de ácidos } \\
\text { nucleicos e inibem as } \\
\text { reações enzimáticas }\end{array}$ & $\begin{array}{c}\text { Metotrexato } \\
\text { 5-Fluorouracilo } \\
\text { Citosina arabinósido } \\
\text { (Citarabina) } \\
\text { Azatioprina }\end{array}$ \\
\hline Alcaloides da vinca & $\begin{array}{l}\text { Impedem a divisão das } \\
\text { células durante a metáfase }\end{array}$ & $\begin{array}{l}\text { Vincristina } \\
\text { Vinblastina }\end{array}$ \\
\hline $\begin{array}{l}\text { Antibióticos } \\
\text { antitumorais }\end{array}$ & $\begin{array}{c}\text { Inibem a transcrição do } \\
\text { DNA }\end{array}$ & $\begin{array}{l}\text { Doxorrubicina } \\
\text { Bleomicina } \\
\text { Actinomicina D } \\
\text { Mitoxantrone }\end{array}$ \\
\hline Hormônios & $\begin{array}{l}\text { Atuam de forma ciclo- } \\
\text { celular específica }\end{array}$ & $\begin{array}{l}\text { Prednisona } \\
\text { Prednisolona }\end{array}$ \\
\hline
\end{tabular}

Fonte: Adaptado de Withrow e MacEWen's,(2007).

Já os fármacos antimetabólitos atuam na síntese de ácidos nucleicos e inibição de reações enzimáticas. São quimioterápicos ciclo-celular específicos, que atuam por ação metabólica causando bloqueio na síntese de DNA. Atuam na fase S do ciclo celular e podem ser divididos em subclasses, de acordo com seu mecanismo de ação, existindo os análogos do ácido fólico, como o metotrexato, os antagonistas das pirimidinas, como a citarabina e floxuridina, e os análogos das purinas, como a mercaptopurina e pentostatina (ALMEIDA et al. 2005). Existem também os alcalóides de vinca, os quais são produtos naturais, ou alcalóides vegetais, que atuam na mitose celular, impedindo a divisão das células durante a metáfase (ALMEIDA et al. 2005).

Por fim, tem-se os agentes antibióticos, que atuam na enzima topoisomerase II, inibindo a transcrição do DNA, e os agentes hormonais, dentre os quais pode-se citar as progestinas, estrogênios, androgênios, antiestrogênio, antiandrogênio, análogo do hormônio liberador de gonadotrofina, inibidor da aromatase e inibidor do hormônio peptídico, que atuam de forma ciclo-celular específica (ALMEIDA et al. 2005). 


\section{DOXORRUBICINA}

A doxorrubicina teve sua eficácia no tratamento do osteossarcoma comprovada na década de 60 . É uma das drogas mais utilizadas nos protocolos quimioterápicos e associações de medicamentos (JAFFE et al. 2013). Nos cães, os primeiros estudos envolvendo essa droga iniciaram-se em 1995, com bons resultados no retardamento da ocorrência de metástases em osteossarcoma apendicular (SZEWCZYK et al. 2015).

É um antibiótico e age por meio da inibição da enzima topoisomerase II. Causa ruptura dos filamentos simples e duplos da fita de DNA (JAFFE et al. 2013), intercalando-se com as moléculas, impedindo a liberação da fita dupla hélice, causando inibição da replicação e promovendo efeitos citotóxicos (RATHORE et al. 2015).

Pode ser administrada sozinha ou em combinação com outros fármacos (JAFFE et al. 2013), normalmente utilizada em doses que variam de 60 a $90 \mathrm{mg} / \mathrm{m}^{2}$ (DÁVIDA et al. 2007). Possui resultados eficazes em pacientes com diferentes tipos de câncer, incluindo pacientes com metástases pulmonares. Além disso, potencializa a ação da radioterapia (JAFFE et al. 2013).

Em cães tratados com doxorrubicina pós-cirúrgica, a sobrevida passou de 138 dias para 366 dias, em comparação aos animais submetidos apenas à cirurgia, o que demonstra que esse agente é eficaz no prolongamento da vida dos animais doentes, no entanto, não possui capacidade de inibir a formação de metástases (SZEWCZYK et al. 2015). Como efeitos adversos desse agente antineoplásico, temse a perda capilar, náuseas, vômitos, disfunção hepática e cardiotoxicidade, podendo causar falência cardíaca (JAFFE et al. 2013, RATHORE et al. 2015).

Outro problema enfrentado no tratamento quimioterápico com a doxorrubicina é a resistência do tumor ao medicamento. Para evitar que isso ocorra, são feitas as combinações entre drogas, como é o caso da combinação entre a doxorrubicina e o tamoxifeno, que melhora a capacidade de matar as células neoplásicas e reduz a resistência tumoral (OUYANG et al. 2013). Já a combinação entre a carboplatina e a doxorrubicina possui atividade antitumoral inferior nos pacientes com osteossarcoma, especialmente naqueles com início de metástase pulmonar (CHOERYPRASERT et al. 2013).

\section{CISPLATINA}

A cisplatina começou a ser usada no tratamento do osteossarcoma na década de 70 e age promovendo efeitos citotóxicos por meio da platinação do DNA (JAFFE et al. 2013). Por ser um agente platinante, impede que haja síntese de novas cópias de DNA e causa bloqueio no processo de transcrição (MEIJER et al. 1999).

Pode ser administrada por via intravenosa ou intra-arterial, sendo esta segunda uma forma de melhorar a eficácia da quimioterapia, já que são atingidas maiores concentrações sistêmicas e um maior efeito citotóxico local, porém requer sedação ou anestesia geral do paciente (JAFFE et al. 2013). Também pode ser administrada pela via intraperitoneal, além de possuir efeito terapêutico em diversos tipos de tumores (DÁVIDA, 2007). Nos cães, acredita-se que o tratamento com essa droga prolongue a taxa de sobrevivência, sendo utilizada como uma terapia adjuvante à cirurgia. No entanto, mesmo o tratamento sendo efetivo, ele não inibe a formação de metástases (SZEWCZYK et al. 2015). 
Como efeito adverso da administração de cisplatina, tem-se a toxicidade renal, o que pode ser minimizado com o suporte da hidratação e diurese. Um dos principais efeitos adversos do uso dessa droga é a ototoxicidade, além de náuseas, vômitos e neuropatia periférica. Também pode haver supressão da medula, causando redução da população de leucócitos, plaquetas e glóbulos vermelhos. Alguns pacientes podem desenvolver anemia hemolítica, convulsões e anormalidades cardíacas (DÁVIDA, 2007).

A combinação desse fármaco com o adenovírus oncolítico $\triangle 24-R G D$ exerce uma potente ação na morte das células de osteossarcoma (VELEZ et al. 2014). Além disso, a associação entre a cisplatina e a metformina também possui efeitos positivos para os pacientes, já que a metformina inibe o crescimento da célula tumoral e amplifica o efeito da cisplatina (QUATTRINI et al. 2014).

\section{CARBOPLATINA}

A carboplatina é um agente derivado da platina e possui atividade antitumoral contra o osteossarcoma. Por ser bem tolerada, é utilizada por apresentar menos efeitos adversos, como a nefrotoxicidade e ototoxicidade, em comparação a outras drogas que atuam pelo mesmo mecanismo de ação, como é o caso da cisplatina (CHOERYPRASERT et al. 2013).

Nos cães, a carboplatina possui atividade similar a da cisplatina, mas não requer intensa diurese salina de suporte e causa menos êmese nos animais tratados. Já nos cães em que a carboplatina foi utilizada como terapia adjuvante após a cirurgia de amputação, houve aumento da sobrevida. Os animais tiveram uma média de sobrevivência de 307 dias, em comparação aos animais submetidos apenas à cirurgia, com sobrevivência de, aproximadamente, 138 dias (SZEWCZYK et al. 2015).

Embora cause menos efeitos adversos, em comparação à cisplatina, a carboplatina causa uma maior mielossupressão, mas, ao contrário da doxorrubicina, não apresenta efeitos cardiotóxicos. Nos cães, pode ser administrada na dose de $300 \mathrm{mg} / \mathrm{m}^{2}$, em ciclos com intervalos de três semanas (SAAM et al. 2011). Na infusão única subcutânea de carboplatina, em cães, como quimioterapia adjuvante para o osteossarcoma, foi possível obter uma média de sobrevivência de 365 dias. Esse fato é semelhante à sobrevida dos animais que receberam infusão intravenosa do mesmo medicamento, por várias semanas. O que demonstra que é possível utilizar doses inferiores, com menores efeitos adversos, para obter os mesmos resultados (SIMCOCK et al. 2012).

Já a associação entre a carboplatina e a gemcitabina após a amputação do membro afetado, em cães com osteossarcoma apendicular, não teve melhores resultados do que os animais tratados apenas com carboplatina. Notou-se que essa associação não promoveu melhorias na taxa de sobrevivência dos animais (MCMAHON et al. 2011).

Em cães tratados com três doses de carboplatina e três doses de doxorrubicina, de forma alternada, os resultados não foram melhores do que nos animais tratados apenas com seis doses de carboplatina. A toxicidade foi a mesma nos dois grupos de tratamento, mostrando que, neste caso, a monoterapia foi mais vantajosa (BEGAS et al. 2014).

\section{METOTREXATO}

O metotrexato é um fármaco da classe dos antimetabólitos, utilizado para o tratamento do osteossarcoma em altas dosagens. É também utilizado no 
tratamento de doenças auto-imunes, e atua na inibição da enzima dihidrofolatoredutase (MCMAHON et al. 2011). Possui efeitos adversos que incluem a disfunção renal, pela dificuldade de excreção do quimioterápico, podendo levar ao desenvolvimento de insuficiência renal aguda em alguns pacientes, caso haja precipitação e acúmulo de metabólitos nos túbulos renais. Essa toxicidade pode ser reduzida pelo uso do leucovorin (DÁVIDA, 2007).

Também é um dos componentes de uma das associações mais utilizadas no tratamento quimioterápico de pacientes com osteossarcoma, composta também pela doxorrubicina e cisplatina, formando uma combinação chamada de MAP (FERRARI et al. 2012).

Foi descoberto na década de 40, e foi um agente importante na cura de crianças com linfoma e leucemia. Ele age privando a célula de folatos, que são essenciais na formação do DNA (JAFFE et al. 2013). É utilizado em altas doses para o tratamento do osteossarcoma, que variam entre 8 a 12g/m² (DÁVIDA, 2007).

Em crianças com osteossarcoma, a exposição ao metotrexato aumento a incidência de efeitos adversos, mas melhorou o tratamento e a taxa de sobreviência dos pacientes. Já a combinação entre a melatonina e o metotrexato, atuando em células de osteossarcoma da linhagem SaOS-2, promoveu um aumento na apoptose das células tumorais, mostrando que a combinação teve um efeito sinérgico (WANG ; YANG, 2015).

Os principais efeitos adversos desse agente têm como alvo a medula óssea e o epitélio intestinal, além de alopecia, dermatites, defeitos na espermatogênese, aborto e teratogênese. Em alguns casos, com exposição prolongada ao metotrexato, pode ocorrer neurotoxicidade, a qual não pode ser revertida pela ação do antídoto (DÁVIDA, 2007).

\section{IFOSFAMIDA E CICLOFOSFAMIDA}

São compostos alquilantes, que atuam na inibição da replicação celular por meio da inserção de um grupo alquila no DNA. Ambos possuem toxicidade semelhante, sendo que com a utilização da ifosfamida, ocorre maior supressão medular, com diminuição do número de plaquetas e neurotoxicidade. A ciclofosfamida possui uma ativação mais rápida em comparação a isofosfamida, porém, causa efeitos adversos como náuseas, vômitos, alopecia e também mielossupresão, só que, ao contrário do que ocorre com a ação da isofosfamida, não ocorre redução no número de plaquetas, ocorrendo neutropenia (DÁVIDA, 2007).

Segundo a literatura, as doses indicadas variam entre 6 a $9 \mathrm{~g} / \mathrm{m}^{2}$ por ciclo, mas doses mais altas, de 12 a $18 \mathrm{~g} / \mathrm{m}^{2}$ são mais eficientes (DÁVIDA, 2007).

Em pacientes com osteossarcoma não-metastático de extremidade foi feito um estudo utilizando metotrexato, cisplatina e doxorrubicina como quimioterapia neoadjuvante, acrescidas ou não de ifosfamida na associação, objetivando melhorar a resposta dos pacientes onde foi utilizada a combinação dos quatro agentes. Nos pacientes em que foi utilizado o protocolo contendo a ifosfamida, não houve melhora na taxa de resposta, e houve ainda um aumento na toxicidade hematológica (FERRARI et al. 2012).

Outro estudo avaliou a ação da ifosfamida em cães com osteossarcoma do tipo metastático. Os cães receberam três doses do composto e, como resultado, houve uma menor resposta ao tumor e ocorrência de toxicidade significativa, com mielossupressão e consequente anemia, trombocitopenia e neutropenia, alterações no trato gastrintestinal e disfunções no sistema renal, concluindo que ainda são necessários estudos envolvendo a ifosfamida para que seja feita a manutenção da 
dose, já que, nos humanos, ela é bastante usada em protocolos alternativos de pacientes com osteossarcoma (BATSCHINSKI et al. 2014).

A ciclofosfamida é comumente utilizada em combinações de agentes antineoplásicos, e se destaca nos protocolos COP (ciclofosfamida, vincristina e prednisona), L-VCAM (L-asparginase, vincristina, ciclofosfamida, doxorrubicina e metotrexato), CHOP (ciclofosfamida, doxorrubicina, vincristina e prednisolona), entre outros. Seus principais efeitos adversos relacionam-se ao sistema renal, sendo que, nos animais, ela pode levar ao desenvolvimento de cistite hemorrágica estéril e neoplasias na bexiga, pela ação tóxica dos seus metabólitos (DÁVIDA, 2007; FERRARI et al. 2012).

\section{TERAPIAS ALTERNATIVAS - microRNA}

Os microRNAs (miRNAs) são pequenos RNAs não codificantes, normalmente formados por 18 a 25 nucleotídeos, que atuam reprimindo a tradução e capturando RNAs mensageiros por emparelhamento de bases na região não traduzida 3' dos genes alvo. Estes possuem potencial para regularem diversos processos biológicos críticos (Quadro 2), incluindo a diferenciação, progressão, apoptose e proliferação de células tumorais (KOBAYASHI et al. 2012).

Os miRNAs são de grande importância no diagnóstico e prognóstico de tumores (SARVER et al. 2013), e, no osteossarcoma, ocorre uma desregulação destas moléculas. Como importância terapêutica, os miRNAs, tais como o miR-192 e miR-215, são responsivos à p53 e são capazes de causar alterações no ciclo celular nas células da linhagem do osteossarcoma. Além disso, o miR34a e miR-31 possuem como alvo vários genes metastáticos, como a integrina $A 5$, radixina $e$ RhoA, indicando seu potencial na prevenção das metástases nos pacientes com osteossarcoma. Outra importância está relacionada ao tratamento quimioterápico, sendo que os miRNAs também são utilizados como biomarcadores da resposta ao osteossarcoma. Um exemplo disso é a expressão aumentada de miR-140 e miR215, que cursa com resistência a vários quimioterápicos, como o metotrexato (VARSHNEY ; SUBRAMANIAN, 2015).

Os miRNAs possuem expressão aumentada no osteossarcoma, como o miR-135b, que tem aumento significante, sendo que essa expressão diferencial pode ser uma consequência do fenótipo maligno (KOBAYASHI et al. 2012).

A expressão de miRNA também indica os níveis de metástases em humanos com osteossarcoma, sendo que, nesse caso, a expressão é reduzida e, níveis intensos de redução indicam um aumento na probabilidade de metástases, com um consequente prognóstico desfavorável (SARVER et al. 2013).

Outra importância está na relação do miRNA com o TP53, que é um gene supressor de tumores envolvido no osteossarcoma. O dano ao DNA induz a fosforilação da p53, causando sua dissociação, que leva a uma supressão tumoral via alteração do ciclo celular ou apoptose. Vários miRNAs foram identificados como sendo alvos diretos da p53. Entre eles, a família miR-34 tem papel importante na via de supressão tumoral desencadeada pela p53 em resposta à danos ao DNA ou estresse oncogênico. A família miR-34 é responsável pela indução de apoptose e interrupção do ciclo celular em células de osteossarcoma, numa via dependente da p53. Já a redução na expressão de miR-31 indica defeitos na via da p53, e a expressão aumentada promove inibição significativa da proliferação de células de osteossarcoma (KOBAYASHI et al. 2012). 


\begin{tabular}{|c|c|}
\hline miRNA & FUNÇÃO \\
\hline $\begin{array}{l}\text { Família miR-34 } \\
\text { (miR-34a, 34b e } \\
\text { 34c) } \\
\text { miR-31 }\end{array}$ & $\begin{array}{l}\text { Atuação na fase G1 do ciclo celular e apoptose, dependente } \\
\text { da p53 } \\
\text { Proliferação celular dependente da p53 }\end{array}$ \\
\hline miR-192, miR-215 & Inibição do ciclo celular dependente da p53 \\
\hline miR-140 & Quimiorresistência ao metotrexato \\
\hline miR-215 & Quimiorresistência ao metotrexato \\
\hline $\begin{array}{l}\text { miR-92a, miR- } \\
\text { 99b, miR-193a- } \\
5 p, m^{2}-422^{a}\end{array}$ & Marcadores de boa ou má resposta aos quimioterápicos \\
\hline miR-21 & Invasão celular e migração \\
\hline miR-199a-3p & Proliferação celular e migração \\
\hline miR-143 & Marcador de metástases pulmonares \\
\hline
\end{tabular}

Fonte: Adaptado de Kobayashi et al. (2012).

\section{INIBIDORES DA ANIDRASE CARBÔNICA IX}

Os tumores sólidos são menos oxigenados, e essa condição faz com que haja menor suprimento para as células e tecidos. Tais condições hipóxicas resultam de um desequilíbrio entre a taxa de proliferação tumoral e a formação de novo tecido endotelial, causando uma desorganização do suprimento vascular. A hipóxia tumoral resulta em um prognóstico negativo, e é um fator que contribui para a quimiorresistência, radioresistência, angiogênese, vasculogênese, formação de metástases e aumento da capacidade de invasão pelo tumor, resistência à morte celular, alterações no metabolismo e instabilidade genômica. Casos de hipóxia prolongada resultam em necrose, com formação de áreas necróticas características dos tumores sólidos (PERUT et al. 2015).

A anidrase carbônica IX (AC9) é uma glicoproteína transmembrana que está envolvida no equilíbrio ácido-base, pois converte reversivelmente o dióxido de carbono e água em ácido carbônico. A AC9 é importante na regulação do pH e em mecanismos de resposta à hipóxia, sendo considerado um marcador intrínseco da hipóxia, também sendo relacionada ao prognóstico desfavorável de vários tipos de carcinoma. É importante na proliferação e transformação celular, bem como a adaptação de células tumorais em condições precárias de oxigênio (PERUT et al. 2015). A expressão de AC9 está relacionada à formação de metástases, maior agressividade do tumor e uma taxa de sobrevivência menor para pacientes com osteossarcoma (PARK et al. 2010). Esta age protegendo as células tumorais da 
hipóxia e da acidose por meio da geração de íons bicarbonato. Sua expressão é aumentada em tumores, mas não em tecidos normais (PERUT et al. 2015), e observa-se esse aumento em vários tipos de carcinomas e tumores sólidos, como o osteossarcoma (PARK et al. 2010).

Inúmeros inibidores da AC9 foram descobertos como sendo agentes antitumorais, mostrando que a inibição dessa enzima é um bom alvo terapêutico (Park et al. 2010). A carnosina, por exemplo, é um agente antineoplásico que inibe a proliferação de células cancerígenas, que age por meio da inibição da anidrase carbônica IX, promovendo aumento do pH extracelular e inibindo o crescimento dos tumores, se mostrando eficaz no tratamento desses tumores (DITTE et al. 2014).

\section{FITOTERÁPICOS - B-LAPACHONA}

A $\beta$-lapachona é um composto derivado das quinonas, obtido a partir do lapachol. É extraído da serragem da madeira das árvores da família Bignoniaceae, conhecidas como ipês (Tabebuia sp.) no Brasil (FERREIRA et al. 2009). O lapachol exerce atividade benéfica em várias doenças, e possui propriedades antibacterianas, antioxidantes e antineoplásicas, além de atuarem no tratamento da toxoplasmose, malária e também no HIV. No osteossarcoma, o derivado do lapachol, a betalapachona, induz apoptose nas células tumorais, promovendo bloqueio do ciclo celular na fase G0/G1 (DÁVIDA, 2007).

A atuação da beta lapachona nas células cancerígenas está relacionada à inibição da reparação do DNA. Ocorre a produção de espécies reativas de oxigênio, como o superóxido, radicais hidroxila, peróxido de hidrogênio e oxigênio singlete, causando estresse oxidativo na célula, com danos irreversíveis a esta, levando a morte celular por apoptose. As quinonas atuam por meio de um ciclo chamado de ciclo redox, onde o subtrato quinonoídico é reduzido e catalisado por enzimas como a NADPH. São geradas as espécies reativas de oxigênio e, posteriormente, os intermediários bioalquilantes, que causam peroxidação lipídica, dano às proteínas e fragmentação do DNA. Além disso, as quinonas atuam nas topoisomerases, enzimas importantes no processo de replicação do DNA, sendo consideradas citotóxicas para as células, cancerígenas ou não (FERREIRA et al. 2009).

\section{LUPEOL}

O lupeol é um composto triterpeno encontrado em vegetais, como o repolho, pimentão, pepino, tomate e frutas, como o figo, a manga, morangos, uvas vermelhas e em plantas medicinais, como American ginseng, Tamarindus indica, Leptadenia hastata, entre outras. Pode ser encontrado na América do Norte, América Latina, Japão, China, África e ilhas caribenhas. Possui atividade antiinflamatória potente, e vem sendo cada vez mais estudado como tratamento alternativo do câncer, com bons resultados em experimentos com câncer de pâncreas, neuroblastoma e adenocarcinoma pulmonar, onde causou inibição da migração de células (SALEEM et al. 2009).

Em células de osteossarcoma humano, o lupeol demonstrou induzir apoptose e inibição do ciclo celular na fase G0/G1, em células da linhagem MG-63 do tumor, o que promete avanços para a descoberta de um tratamento efetivo para a doença (LIU et al. 2015). 


\section{CONSIDERAÇÕES FINAIS}

O osteossarcoma é um tumor agressivo, com baixa taxa de sobrevivência, cujo tratamento envolve a remoção cirúrgica do membro afetado, associada a protocolos quimioterápicos com altas dosagens, o que faz com que o paciente, seja ele um ser humano ou um cão, tenha inúmeros efeitos adversos, além da limitação física.

Muitos protocolos não apresentam bons resultados no tratamento desses tumores, e os pacientes podem desenvolver resistência aos fármacos utilizados. Isso mostra que é importante que sejam feitas mais pesquisas e experimentos visando novas formas de tratamento e o desenvolvimento de novos agentes antineoplásicos, que promovam maiores efeitos citotóxicos ao tumor, com menores efeitos negativos ao paciente.

O avanço das pesquisas para o desenvolvimento de terapias alternativas à quimioterapia vem aumentando a expectativa de cura dos pacientes, e muitos pesquisadores estão em busca de novos fármacos, vários deles provenientes das plantas e frutos, onde existe matéria-prima em abundância para a formulação de vários medicamentos, sendo que vários desses agentes fitoterápicos induzem citotoxicidade nas células tumorais, com ação comprovada em muitas outras doenças, trazendo bons resultados e menores efeitos adversos aos doentes, despertando cada vez mais o interesse da ciência.

Outro ponto de questionamento dos pesquisadores é o fato de que os quimioterápicos não atuam de forma seletiva, sendo inespecíficos, e agindo tanto nas células neoplásicas, quanto nas células normais do paciente, o que causa efeitos negativos a este. $O$ avanço da biologia molecular é importante para 0 desenvolvimento de marcadores específicos das células tumorais, em busca da destruição apenas das células cancerígenas.

Conhecendo os mecanismos de ação desses fármacos e suas formas de atuação, é possível lançar mão de novos protocolos para o tratamento do osteossarcoma, além de promover maior incentivo às pesquisas e experimentos, mostrando que existem várias outras possibilidades de tratamento que devem ser testadas, e muitas outras a serem descobertas.

\section{REFERÊNCIAS}

ALMEIDA, VERA LÚCIA DE ET AL. LMEIDA, V. L. D., LEITÃO, A., REINA, L. D. C. B., MONTANARI, C. A., DONNICI, C. L., LOPES, M. T. P. Câncer e agentes antineoplásicos ciclo-celular específicos e ciclo-celular não específicos que interagem com o DNA: uma introdução. Química Nova, v. 28, n. 1, p. 118-129, 2005. Disponível em < http://www.scielo.br/pdf/\%0D/qn/v28n1/23048.pdf >. doi: 10.1590/S0100-40422005000100021.

BAILEY, D., ERB, H., WILLIAMS, L., RUSLANDER, D., HAUCK, M. Carboplatin and doxorubicin combination chemotherapy for the treatment of appendicular osteosarcoma in the dog. Journal of veterinary internal medicine, v. 17, n. 2, p. 199-205, 2003. Disponível em < http://onlinelibrary.wiley.com/doi/10.1111/j.19391676.2003.tb02434.x/full >. doi: 10.1111/j.1939-1676.2003.tb02434.x.

BATSCHINSKI, K.; DERVISIS, N. G.; KITCHELL, B. E. Evaluation of ifosfamide salvage therapy for metastatic canine osteosarcoma. Veterinary and comparative oncology, v. 12, n. 4, p. 249-257, 2014. Disponível em < 
http://onlinelibrary.wiley.com/doi/10.1111/j.1476-5829.2012.00355.x/full >. doi: 10.1111/j.1476-5829.2012.00355.x.

BEGAS, E., PAPANDREOU, C., TSAKALOF, A., DALIANI, D., PAPATSIBAS, G., ASPRODINI, E. Simple and reliable HPLC method for the monitoring of methotrexate in osteosarcoma patients. Journal of chromatographic science, v. 52, n. 7, p. 590595, 2013. Disponível em < https://academic.oup.com/chromsci/article/52/7/590/520699/Simple-and-ReliableHPLC-Method-for-the-Monitoring >. doi: 10.1093/chromsci/bmt081.

CHOEYPRASERT, W., NATESIRINILKUL, R., CHAROENKWAN, P., \& SITTIPREECHACHARN, S. Carboplatin and doxorubicin in treatment of pediatric osteosarcoma: a 9-year single institute experience in the Northern Region of Thailand. Asian Pacific Journal of Cancer Prevention, v. 14, n. 2, p. 1101-6, 2013. Disponível em http://koreascience.or.kr/article/ArticleFullRecord.jsp?cn=POCPA9_2013_v14n2_110 1 >. doi: 10.7314/APJCP.2013.14.2.1101.

COOLEY, D. M., BERANEK, B. C., SCHLITTLER, D. L., GLICKMAN, N. W., GLICKMAN, L. T., WATERS, D. J. Endogenous gonadal hormone exposure and bone sarcoma risk. Cancer Epidemiology and Prevention Biomarkers, v. 11, n. 11, p. 1434-1440, 2002. Disponível em < http://cebp.aacrjournals.org/content/11/11/1434.short >.

DÁVIDA, D. S. Osteossarcoma: tratamento quimioterápico [Tese]. f. 68, São Paulo: Centro Universitário das Faculdades Metropolitanas Unidas, 2007. Disponível em < http://arquivo.fmu.br/prodisc/farmacia/dsd.pdf $>$.

DE CASTRO, H. C., RIBEIRO, K. D. C. B., BRUNIERA, P. Osteossarcoma\&58; experiência do Serviço de Oncologia Pediátrica da Santa Casa de Misericórdia de São Paulo Osteosarcoma\&58; experience of the Pediatric Oncology clinic of the Santa Casa de Misericórdia Hospital in São Paulo. Revista Brasileira de Ortopedia, v. 43, n. 4, p. 108-115, 2008. Disponível em < http://www.ingentaconnect.com/content/doaj/01023616/2008/00000043/00000004/art 00002 >. doi: 10.1590/S0102-36162008000300002.

DITTE, Z., DITTE, P., LABUDOVA, M., SIMKO, V., IULIANO, F., ZATOVICOVA, M. et al. Carnosine inhibits carbonic anhydrase IX-mediated extracellular acidosis and suppresses growth of HeLa tumor xenografts. BMC cancer, v. 14, n. 1, p. 358, 2014. Disponível em < https://bmccancer.biomedcentral.com/articles/10.1186/1471-240714-358 >. doi: 10.1186/1471-2407-14-358.

FAUSKE, L., BONDEVIK, H., BRULAND, Ø. S., OZAKINCI, G. Negative and positive consequences of cancer treatment experienced by long-term osteosarcoma survivors: A qualitative study. Anticancer research, v. 35, n. 11, p. 6081-6090, 2015. Disponível em < http://ar.iiarjournals.org/content/35/11/6081.short >.

FERRARI, S., RUGGIERI, P., CEFALO, G., TAMBURINI, A., CAPANNA, R., FAGIOLI, F. et al. Neoadjuvant chemotherapy with methotrexate, cisplatin, and doxorubicin with or without ifosfamide in nonmetastatic osteosarcoma of the 
extremity: an Italian sarcoma group trial ISG/OS-1. Journal of clinical oncology, v. 30 , n. 17, p. 2112-2118, 2012. Disponível em < http://ascopubs.org/doi/abs/10.1200/jco.2011.38.4420 >. doi: 10.1200/JCO.2011.38.4420.

FERREIRA, S. B., GONZAGA, D. T. G., SANTOS, W. C., ARAÚJO, K. G. L., FERREIRA, V. F. beta-Lapachona: Sua importância em química medicinal e modificações estruturais. Revista Virtual de Química, v. 2, n. 2, p. 140-160, 2010. Disponível em https://www.researchgate.net/profile/Daniel Gonzaga4/publication/277160708 Lapa chona_Sua_importancia_em_quimica_medicinal_e_modificacoes_estruturais/links/5 59fbe1f08ae3dbcbe86ed74/Lapachona-Sua-importancia-em-quimica-medicinal-emodificacoes-estruturais.pdf $>$.

HATTINGER, C. M., FANELLI, M., TAVANTI, E., VELLA, S., FERRARI, S., PICCI, P., SERRA, M. Advances in emerging drugs for osteosarcoma. Expert opinion on emerging drugs, v. 20, n. 3, p. 495-514, 2015. Disponível em < http://www.tandfonline.com/doi/abs/10.1517/14728214.2015.1051965 >. doi: 10.1517/14728214.2015.1051965.

HEGYI, M., GULÁCSI, Á., CSÁGOLY, E., CSORDÁS, K., EIPEL, O. T., ERDÉLYI, D. $\mathrm{J}$ et al. Clinical relations of methotrexate pharmacokinetics in the treatment for pediatric osteosarcoma. Journal of cancer research and clinical oncology, v. 138, n. $10, \quad$ p. 1697-1702, 2012. Disponível em < https://link.springer.com/article/10.1007/s00432-012-1214-2 >. doi: 10.1007/s00432012-1214-2.

ISAKOFF, M. S., BIELACK, S. S., MELTZER, P., GORLICK, R. Osteosarcoma: current treatment and a collaborative pathway to success. Journal of clinical oncology, v. 33, n. 27, p. 3029-3035, 2015. Disponível em < http://ascopubs.org/doi/abs/10.1200/jco.2014.59.4895 >. doi: 10.1200/JCO.2014.59.4895.

JAFFE, N., PURI, A., GELDERBLOM, H. Osteosarcoma: evolution of treatment paradigms. Sarcoma, v. 2013, 2013. Disponível em < https://www.hindawi.com/journals/sarcoma/2013/203531/ >. doi: $10.1155 / 2013 / 203531$.

KOBAYASHI, E., HORNICEK, F. J., \& DUAN, Z. MicroRNA involvement in osteosarcoma. Sarcoma, $\quad$ v. 2012. http://downloads.hindawi.com/journals/srcm/2012/359739.pdf 10.1155/2012/359739 LIU, Y., BI, T., WANG, G., DAI, W., WU, G., QIAN, L. et al. Lupeol inhibits proliferation and induces apoptosis of human pancreatic cancer PCNA-1 cells through AKT/ERK pathways. Naunyn-Schmiedeberg's archives of pharmacology, v. 388, n. 3, p. 295-304, 2015.

MARTINEZ-VELEZ, N., XIPELL, E., JAUREGUI, P., ZALACAIN, M., MARRODAN, L., ZANDUETA, C. et al. The Oncolytic Adenovirus $\triangle 24-R G D$ in Combination With Cisplatin Exerts a Potent Anti-Osteosarcoma Activity. Journal of Bone and Mineral 
Research, v. 29, n. 10, p. 2287-2296, 2014. Disponível em < http://onlinelibrary.wiley.com/doi/10.1002/jbmr.2253/full >. doi: 10.1002/jbmr.2253.

MCMAHON, M., MATHIE, T., STINGLE, N., ROMANSIK, E., VAIL, D., \& LONDON, C. Adjuvant carboplatin and gemcitabine combination chemotherapy postamputation in canine appendicular osteosarcoma. Journal of veterinary internal medicine, $v$. 25, n. 3, p. 511-517, 2011. Disponível em < http://onlinelibrary.wiley.com/doi/10.1111/j.1939-1676.2011.0697.x/full >. doi: 10.1111/j.1939-1676.2011.0697.x.

MEIJER, C., DE VRIES, E. G., MARMIROLI, P., TREDICI, G., FRATTOLA, L., CAVALETTI, G. Cisplatin-induced DNA-platination in experimental dorsal root ganglia neuronopathy. Neurotoxicology, v. 20, n. 6, p. 883-887, 1999. Disponível em < http://europepmc.org/abstract/med/10693969 >.

OUYANG, Z. X; LI, X. A. Inhibitory effects of tamoxifen and doxorubicin, alone and in combination, on the proliferation of the MG63 human osteosarcoma cell line. Oncology letters, v. 6, n. 4, p. 970-976, 2013. Disponível em < https://www.spandidos-publications.com/10.3892/ol.2013.1487 >. doi: 10.3892/ol.2013.1487.

PARK, H. R., SEO, J., BACCHINI, P., BERTONI, F., PARK, Y. K. Expression of Carbonic Anhydrase IX Correlates with Histologic Grade and Metastasis in Osteosarcoma. Korean Journal of Pathology, v. 44, n. 4, p. 384-389, 2010. Disponível em < http://jpatholtm.org/upload/pdf/kjp-44-4-384.pdf >. doi: 10.4132/KoreanJPathol.2010.44.4.384.

PERUT, F., CARTA, F., BONUCCELLI, G., GRISENDI, G., DI POMPO, G., AVNET, S. et al. Carbonic anhydrase IX inhibition is an effective strategy for osteosarcoma treatment. Expert opinion on therapeutic targets, v. 19, n. 12, p. 1593-1605, 2015. Disponível em http://www.tandfonline.com/doi/abs/10.1517/14728222.2016.1086339 >. doi: 10.1517/14728222.2016.1086339.

PICCI, P.; Osteosarcoma (osteogenic sarcoma). Orphanet journal of rare diseases, $\quad$ v. 2, n. 1, p. 6, 2007. Disponível em < https://ojrd.biomedcentral.com/articles/10.1186/1750-1172-2-6 >. doi: 10.1186/17501172-2-6.

QUATTRINI, I., CONTI, A., PAZZAGLIA, L., NOVELLO, C., FERRARI, S., PICCI, P., BENASSI, M. S. Metformin inhibits growth and sensitizes osteosarcoma cell lines to cisplatin through cell cycle modulation. Oncology reports, v. 31, n. 1, p. 370-375, 2014. Disponível em < https://www.spandidospublications.com/10.3892/or.2013.2862?text=abstract $>$. doi: 10.3892/or.2013.2862.

RATHORE, K; CEKANOVA, M. A novel derivative of doxorubicin, AD198, inhibits canine transitional cell carcinoma and osteosarcoma cells in vitro. Drug design, development and therapy, v. 9, p. 5323, 2015. Disponível em < https://www.ncbi.nlm.nih.gov/pmc/articles/PMC4590339/ >. doi: 10.2147/DDDT.S90859. 
SAAM, D. E., LIPTAK, J. M., STALKER, M. J., \& CHUN, R. Predictors of outcome in dogs treated with adjuvant carboplatin for appendicular osteosarcoma: 65 cases (1996-2006). Journal of the American Veterinary Medical Association, v. 238, n. 2, p. 195-206, 2011. Disponível em < http://avmajournals.avma.org/doi/abs/10.2460/javma.238.2.195?journalCode=javma >. doi: 10.2460/javma.238.2.195.

SALEEM, M. LUPEOL, a novel anti-inflammatory and anti-cancer dietary triterpene. Cancer letters, v. 285, n. 2, p. 109-115, 2009. Disponível em < http://www.sciencedirect.com/science/article/pii/S0304383509003000 >. doi: 10.1016/j.canlet.2009.04.033.

SARVER, A. L., THAYANITHY, V., SCOTT, M. C., CLETON-JANSEN, A. M., HOGENDOORN, P. C., MODIANO, J. F. et al. MicroRNAs at the human 14q32 locus have prognostic significance in osteosarcoma. Orphanet journal of rare diseases, v. $8, \quad$ n. $1, \quad$ p. 7,2013 . Disponível em < https://ojrd.biomedcentral.com/articles/10.1186/1750-1172-8-7 >. doi: 10.1186/17501172-8-7.

SIMCOCK, J. O., WITHERS, S. S., PRPICH, C. Y., KUNTZ, C. A., RUTLAND, B. E. Evaluation of a single subcutaneous infusion of carboplatin as adjuvant chemotherapy for dogs with osteosarcoma: 17 cases (2006-2010). Journal of the American Veterinary Medical Association, v. 241, n. 5, p. 608-614, 2012. Disponível em http://avmajournals.avma.org/doi/abs/10.2460/javma.241.5.608?journalCode=javma >. doi: 10.2460/javma.241.5.608.

SKORUPSKI, K. A., UHL, J. M., SZIVEK, A., ALLSTADT FRAZIER, S. D., REBHUN, R. B., \& RODRIGUEZ, C. O. Carboplatin versus alternating carboplatin and doxorubicin for the adjuvant treatment of canine appendicular osteosarcoma: a randomized, phase III trial. Veterinary and comparative oncology, v. 14, n. 1, p. 81-87, 2016. Disponível em < http://onlinelibrary.wiley.com/doi/10.1111/vco.12069/full >. doi: 10.1111/vco.12069.

SZEWCZYK, M., LECHOWSKI, R., ZABIELSKA, K. What do we know about canine osteosarcoma treatment?-review. Veterinary research communications, v. 39, n. 1, p. 61-67, 2015. Disponível em < https://link.springer.com/article/10.1007/s11259014-9623-0 >. doi: 10.1007/s11259-014-9623-0.

VARSHNEY, J; SUBRAMANIAN, S. MicroRNAs as potential target in human bone and soft tissue sarcoma therapeutics. Frontiers in molecular biosciences, v. 2, 2015. Disponível em < https://www.ncbi.nlm.nih.gov/pmc/articles/PMC4470082/ >. doi: 10.3389/fmolb.2015.00031.

WANG, Y. P.; YANG, Z. P. Effects of melatonin combined with Cis-platinum or methotrexate on the proliferation of osteosarcoma cell line SaOS-2. Zhongguo yi xue ke xue yuan xue bao. Acta Academiae Medicinae Sinicae, v. 37, n. 2, p. 215-220, 2015. Disponível em < http://europepmc.org/abstract/med/25936711 >. doi: 10.3881/j.issn.1000-503X.2015.02.013. 
WITHROW, S. J, VAIL, D. M. Small animal clinical oncology. 4 ed. Saunders Elsevier; 2007. 846p. 